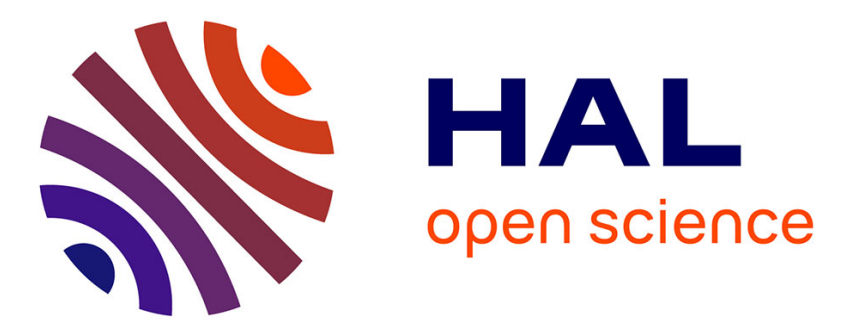

\title{
Electroporation-Induced Stress Response and Its Effect on Gene Electrotransfer Efficacy: In Vivo Imaging and Numerical Modeling
}

Tadeja Forjanic, Bostjan Markelc, Marija Marcan, Elisabeth Bellard, Franck Couillaud, Muriel Golzio, Damijan Miklavci

\section{To cite this version:}

Tadeja Forjanic, Bostjan Markelc, Marija Marcan, Elisabeth Bellard, Franck Couillaud, et al.. Electroporation-Induced Stress Response and Its Effect on Gene Electrotransfer Efficacy: In Vivo Imaging and Numerical Modeling. IEEE Transactions on Biomedical Engineering, 2019, 66 (9), pp.2671-2683. 10.1109/TBME.2019.2894659 . hal-02390782

\section{HAL Id: hal-02390782 \\ https://hal.science/hal-02390782}

Submitted on 9 Dec 2020

HAL is a multi-disciplinary open access archive for the deposit and dissemination of scientific research documents, whether they are published or not. The documents may come from teaching and research institutions in France or abroad, or from public or private research centers.
L'archive ouverte pluridisciplinaire HAL, est destinée au dépôt et à la diffusion de documents scientifiques de niveau recherche, publiés ou non, émanant des établissements d'enseignement et de recherche français ou étrangers, des laboratoires publics ou privés. 


\title{
Electroporation induced stress response and its effect on gene electrotransfer efficacy: in vivo imaging and numerical modelling
}

\author{
Tadeja Forjanič ${ }^{1, *}$, Boštjan Markelc ${ }^{2,3, *}$, Marija Marčan ${ }^{1}$, Elisabeth Bellard ${ }^{2}$, Franck Couillaud ${ }^{4}$, \\ Muriel Golzio ${ }^{2, \dagger}$ and Damijan Miklavčič ${ }^{1, \dagger}$.
}

\begin{abstract}
Objective: Skin is an attractive target tissue for gene transfer due to its size, accessibility and its immune competence. One of the promising delivery methods is gene delivery by means of electroporation (EP), i.e. gene electrotransfer (GET). To assess the importance of different effects of electroporation for successful GET we investigated: i) stress response and ii) transfection efficacy upon different pulse protocols. Moreover, numerical modelling was used to explain experimental results and to test the agreement of experimental results with current knowledge about GET. Methods: Double transgenic mice Hspa1b-LucF $(+/+)$ Hspa1b-mPlum (+/+) were used to determine the level of stress sensed by the cell in the tissue in vivo that was exposed to EP. The effect of five different pulse protocols on stress levels sensed by the exposed cells and their efficacy for gene electrotransfer for two plasmids pEGFP-C1 (EGFP) and pCMV-tdTomato was tested. Results: Quantification of the bioluminescence signal intensity shows that EP, regardless of the electric pulse parameters used, increased mean bioluminescence compared to the baseline bioluminescence signal of the non-exposed skin. The results of numerical modelling indicate that thermal stress alone is not sufficient to explain the measured bioluminescence signal. Of the tested pulse protocols, the highest expression of EGFP and tdTomato was achieved with HV-MV (high voltage - medium voltage) protocols, which agrees also with numerical model. Significance: Although EP is widely used as a method for gene delivery, we show that the field could benefit from the use of mathematical modelling by introducing additional parameters such as EP induced stress and electrophoretic movement of plasmids.
\end{abstract}

Index Terms - electroporation, gene electrotransfer, numerical modelling, skin electroporation

Copyright (c) 2017 IEEE. Personal use of this material is permitted However, permission to use this material for any other purposes must be obtained from the IEEE by sending an email to pubs-permissions@ ieee.org.

*T. Forjanič was with the Department for Biomedical Engineering, Faculty of Electrical Engineering, University of Ljubljana, Tržaška 25, 1000, Ljubljana, Slovenia. She is now with the Institute of Oncology Ljubljana, Zaloška cesta 2, 1000, Ljubljana, Slovenia (email: tforjanic@ onko-i.si).

*B. Markelc was with the Institut de Pharmacologie et Biologie Structurale, IPBS, Université de Toulouse, CNRS, UPS, BP 64182, 205 Route de Narbonne, F-31077, Toulouse, France. He is now with CRUK/MRC Oxford Institute for Radiation Oncology, Old Road Campus Research Building, Roosevelt Drive, Oxford, OX3 7DQ (email: bostjan.markelc@ oncology.ox.ac.uk).

M. Marčan is with the Department for Biomedical Engineering, Faculty of Electrical Engineering, University of Ljubljana, Tržaška 25, 1000, Ljubljana, Slovenia (email: marija.marcan@gmail.com).

\section{INTRODUCTION}

S KIN is an attractive target tissue for gene transfer due to its $N_{\text {large surface and its accessibility. Moreover, skin contains }}$ antigen-presenting cells and is, thus, a particularly suitable target for DNA vaccination [1], [2], [3]. However, in order to reach the cellular nucleus of the target cell in the tissue, naked DNA has to overcome several barriers/limitations. These include poor mobility of DNA and its rapid degradation in the extracellular space of the tissue, low permeability of the cellular membrane, which prevents naked DNA to enter the cell, and poor mobility of the DNA inside the cell [4]. One of the promising delivery methods is gene delivery by means of electroporation (EP) [5]-[9]. This delivery method, termed gene electrotransfer (GET), is based on the application of electric pulses, which generate sufficiently high electric fields to achieve increased cell membrane permeability due to the phenomenon, called EP. Moreover, electric pulses also generate electrophoretic force, which promotes directional movement of naked DNA within the extracellular space and pushes DNA towards the cell membrane [10]-[14]. Efficient GET requires a careful control of pulse parameters and appropriate choice of electrode configuration [15], [16]. In order to achieve successful gene expression, it is also necessary to avoid excessive cellular damage. Moreover, EP itself represents a stress for the cell, which together with membrane resealing is energy consuming and, therefore, can compete with the ability of the cell to start expressing the transfected gene. Recently it was shown that GET of plasmid DNA can upregulate the expression of cytosolic DNA sensors which can in turn lead to release of proinflammatory cytokines resulting in

E.Bellard is with the Institut de Pharmacologie et Biologie Structurale, IPBS, Université de Toulouse, CNRS, UPS, BP 64182, 205 Route de Narbonne, F-31077, Toulouse, France (email: bellard@ipbs.fr).

F. Couillaud is with the Molecular Imaging and Innovative therapies in Oncology (IMOTION), EA 7435/University of Bordeaux, 146 rue Leo Saignat, 33076 Bordeaux, France (email: franck.couillaud@u-bordeaux.fr).

$\dagger \mathrm{M}$. Golzio is with the Institut de Pharmacologie et Biologie Structurale, IPBS, Université de Toulouse, CNRS, UPS, BP 64182, 205 Route de Narbonne, F-31077, Toulouse, France (correspondence email: muriel.golzio@ipbs.fr, Telephone: +33(0)561175813, Fax: +33(0)561175994).

$\dagger$ D. Miklavčič is with the Department for Biomedical Engineering, Faculty of Electrical Engineering, University of Ljubljana, Tržaška 25, 1000, Ljubljana, Slovenia (correspondence email: damijan.miklavcic@fe.uni-lj.si, Telephone: +38614768 456). 
inflammation, thus adding additional level of stress that the electroporated cell is exposed to [17].

Expression of heat shock proteins (HSP) is observed when cells are exposed to elevated temperatures. HSP's are, however, non-specific proteins, meaning their synthesis is not induced only by elevated temperatures, but also by variety of other stressful conditions such as infection, inflammation, exercise, exposure of the cell to toxins (ethanol, arsenic, trace metals, and ultraviolet light, among many others), starvation, hypoxia (oxygen deprivation), or water deprivation [18]. HSP's can also be induced by EP [19], [20]. One can determine the expression of HSP's in vivo by using transgenic mouse models where bioluminescent or fluorescent reporter genes are linked to HSP promoters. In these models, the level of the expression of HSP's can be readily determined by measuring the emitted bioluminescent or fluorescent signal [21], [22]. It is important to distinguish between thermal damage and bioluminescence intensity as a measure of HSP's expression, which are two fundamentally different processes. The former is Arrhenius relationship accounting for temperature- and time-dependency of the thermal damage, which is usually quantified in terms of cell survival or protein denaturation while the latter describes HSP promoter activation. It has been namely shown that HSP expression caused by thermal stress also follows Arrhenius relationship in vitro [23] as well as in vivo [24]. The relationship between EP and upregulation of HSP expression, nevertheless, remains unknown.

To assess the importance of different effects of EP on successful GET, the aims of our study included: i) evaluating the stress response to EP using a transgenic mouse model that allows firefly luciferase (LucF) expression under the control of the thermo-inducible heat-shock protein $(\mathrm{Hsp} 70)$ promoter 1B (Hspa1b), ii) comparing transfection efficacy of different pulse protocols for GET of plasmids coding for fluorescent proteins. Moreover, numerical modelling was used as a tool to explain experimental results and to challenge the agreement of experimental results with current knowledge about GET.

\section{MAteriAls AND MethodS}

\section{A. In vivo experiments}

1) Mice

Animal experiments were performed in agreement with European directives and conducted in accordance with French procedural guidelines for animal handling and with approval from the Regional Ethical Review Committee (MP/02/36/10/10). The double transgenic mice Hspalb-LucF $(+/+)$ Hspa1b-mPlum (+/+) [21], [22] were maintained under $12 \mathrm{~h}$ light/dark cycle with water and food ad libitum. One day before the experiments, the back of mice was shaved with clippers and a depilatory cream was applied to remove the hair. For the Bioluminescence experiments we have used 6 mice per group for positive controls of bioluminescence induction (different temperature in water bath) where a high and repeatable induction of bioluminescence was observed. For the rest of the experiments 12 mice per group were used. For gene expression experiments, 6 mice per group were used.
Experiments were performed in two separate batches.

\section{2) Reagents}

D-luciferin Na salt (OZBIOSCEINCES ) was dissolved in $1 \mathrm{x}$ Dulbecco's phosphate-buffered saline (DPBS, Gibco) without $\mathrm{MgCl}_{2}$ and $\mathrm{CaCl}_{2}$ to a final concentration of $30 \mathrm{mg} / \mathrm{mL}$, filtered through a $0.2 \mu \mathrm{m}$ filter and stored at $-80^{\circ} \mathrm{C}$ until further use. Plasmids pEGFP-C1 (EGFP) and pCMV-tdTomato (tdTomato) (both from Clontech) were isolated from competent $E$. coli with EndoFree Plasmid Mega Kit (Qiagen) according to manufacturers' instructions. Purity and quantity of the isolated plasmid DNA was confirmed by determining the 260/230 and 260/280 ratios with NanoDrop (ThermoFisher). The isolated plasmid DNA was dissolved in sterile $\mathrm{H}_{2} \mathrm{O}$ and stored at $-20^{\circ} \mathrm{C}$.

\section{3) Electroporation and gene electrotransfer}

EP was carried out one day after shaving and depilating the mouse. Electric pulses were delivered by stainless steel contact electrodes (4 mm apart, length $10 \mathrm{~mm}, 2 \mathrm{~mm}$ diameter) connected to electropulsator (ELECTRO cell B10 HVLV (ßtech-Leroy biotech, France)). Good contact was assured by means of conductive gel (Eko-gel, Egna, Italy). Except in control mice where nothing was injected, either $25 \mu \mathrm{L}$ of phosphate buffered saline (PBS, Gibco) or plasmid DNA (tdTomato or EGFP, $25 \mu \mathrm{g}(1 \mu \mathrm{g} / \mu \mathrm{L}))$ was injected intradermally immediately ( $5 \mathrm{~s}$ ) prior to the delivery of electric pulses. Five different pulse protocols were used in experiments: 1) short, high voltage pulses used as in electrochemotherapy (HV) [25], 2) long, high voltage pulses used for GET to tumours (EGT) [26], 3) long, medium voltage pulses used in skin electrotransfer (MV) [27], [28], 4) HV + MV unipolar pulses and 5) HV + MV bipolar pulses [29], [30] (Table I, Supp. Fig. $1)$.

TABLE I PULSE PROTOCOLS USED IN EXPERIMENTS

\begin{tabular}{|l|l|l|l|}
\hline $\begin{array}{l}\text { Electric pulse } \\
\text { protocol }\end{array}$ & $\begin{array}{l}\text { Voltage } \\
{[\mathrm{V}]}\end{array}$ & $\begin{array}{l}\text { Duration of } \\
\text { pulses }[\mathrm{ms}]\end{array}$ & $\begin{array}{l}\text { Frequency } \\
{[\mathrm{Hz}]}\end{array}$ \\
\hline HV & 400 & $8 \times 0.1$ & 1 \\
\hline EGT & 240 & $8 \times 5$ & 1 \\
\hline MV & 100 & $8 \times 20$ & 1 \\
\hline $\begin{array}{l}\text { HV+MV unipolar* } \\
\text { HV+MV bipolar* }\end{array}$ & $400+100$ & $4 \times 0.1 ; 4 \times 20$ & $1 ; 1$ \\
\hline
\end{tabular}

*HV + MV protocols consisted of $4 \mathrm{HV}$ pulses, each followed by one MV pulse with $50 \mathrm{~ms}$ delay. Altogether 8 pulses were delivered, as in other protocols

\section{B. Image acquisition and analysis}

\section{1) Bioluminescence}

In vivo bioluminescence imaging was performed $6 \mathrm{~h}$ after $\mathrm{EP}$ or control treatment, when the expression of Hspalb-induced LucF is highest [21], [22]. As a positive control, the right hind leg of a mouse was submerged for 8 min in a water bath with automatic temperature regulation set at 45 degrees Celsius while the rest of their body was lying on isolation material to prevent heating of the mouse. Mice were injected with $100 \mu \mathrm{L}$ of luciferin ( $3 \mathrm{mg} /$ mouse) intraperitoneally (ip) 5 min prior to imaging. Animals were anaesthetized with inhalation anaesthesia (2\% Isoflurane in air, Vetflurane, VIRBAC-France) delivered by a MiniHub station (TEM-Sega) throughout the 
experiment. Bioluminescence imaging was performed using a home-built system comprising of a Light box (Photek) equipped with a cooled CCD camera (Andor iKon M, Belfast, UK), a Schneider objective VIS-NIR (Cinegon 1.4/12-0515) and a heating blanket (Harvard Apparatus) to maintain the temperature of mice. Images were acquired with Solis acquisition software (Andor technology) with the following parameters: 16bit, $4 \times 4$ binning, 5 min exposure, 6 consecutive images in a series.

Bioluminescence images were processed using FIJI [31] in the following way: i) from each image in a series a fixed value of 300 was subtracted to correct for background pixel intensity, ii) two regions of interest (ROI) were drawn on each mouse, one around the position of electrodes (ROI EP) and the second one on a part of the skin that was not exposed to EP (ROI ctrl), iii) mean pixel intensity from ROI ctrl was used as a threshold in ROI EP to determine the area exhibiting bioluminescent signal above baseline, iv) the ratio of mean pixel intensity ROI $\mathrm{EP} / \mathrm{ROI}$ ctrl was calculated for each image in a series to give a normalized increase of bioluminescence intensity, v) the highest ROI EP/ROI ctrl ratio from an image series was used in subsequent analysis. To determine average bioluminescence intensity profiles, we first drew a line parallel to the original direction of the electrodes. Then, this line was shifted from the beginning to the end of the region of interest (ROI) one pixel at a time. At each step, we calculated the average intensity along the line, which represents an individual data point of the profile. The same procedure was used to obtain the average simulated profiles.

\section{2) Fluorescence}

In vivo fluorescence microscopy was carried out using an upright "Macrofluo" fluorescence macroscope (Leica Microsystems SA, Rueil-Malmaison, France), equipped with a Cool Snap HQ Camera (Roper Scientific, Photometrics, Tucson, AZ, USA). Animals were anaesthetized with inhalation anaesthesia (Isoflurane, Belamont) throughout the experiment. EGFP and tdTomato expression was imaged by fluorescence using specific filters (excitation filters; BP 480/40 nm (EGFP), BP 560/40 nm (tdTomato), emission filters: BP 527/30 nm (EGFP), BP 630/75 nm (tdTomato)). Exposure was kept constant between mice and neutral density (ND) filters were used to prevent overexposure. Each mouse was imaged daily for 16 days.

The expression of EGFP and tdTomato in mice after EP was measured as mean pixel intensity in the transfected area. The transfected area was determined using Otsu thresholding and morphological operations (image opening, image closing) in Matlab. The mean pixel intensity of the thresholded area was then measured for each image, adjusted to account for any ND filters used, and background intensity (determined as mean pixel intensity of the non-transfected skin). The obtained value was then normalized to the highest value in the entire dataset for tdTomato and EGFP separately to give the fraction of the maximum measured mean intensity (fraction of Imax). For each mouse, the highest determined fraction of Imax from the daily imaging series was used in the subsequent analysis. To determine average fluorescence intensity profiles after EP, a
400 pixels thick line was drawn perpendicularly to the position of electrodes on the image obtained 1 day after EP in FIJI software and the mean pixel intensity (of the 400 pixels) for each pixel on the length of the line was calculated.

\section{Numerical model of the skin}

\section{1) Bioluminescence}

Skin was modelled as a three-dimensional multilayered structure with following layers [5], [32]: stratum corneum, epidermis, dermis, adipose tissue, muscle tissue and subcutaneous tissue (Table II). The thickness of the subcutaneous layer was increased in order to reduce the effect of boundary on simulation results. To achieve successful skin EP using non-invasive electrodes, appropriate electric pulses have to be selected to overcome the high resistance of stratum corneum, the superficial layer of the skin. After exceeding EP threshold, resistance of stratum corneum drops for 2-3 orders of magnitude, thus enabling EP of underlying layers [33]. This drop in resistance occurs due to formation of local conductive pathways [34], which were introduced in the model as small cylinders with initial diameter of $10 \mu \mathrm{m}$. During the pulses, the size of local conductive pathways increases if the local temperature rises to around $70^{\circ} \mathrm{C}$ [35], a phase transition temperature of stratum corneum lipids. Local conductive pathway expansion due to Joule heating was modelled as an irreversible phase change at the temperature range $65^{\circ} \mathrm{C}-75^{\circ} \mathrm{C}$ with the latent heat of $5300 \mathrm{~J} / \mathrm{kg}$ [36]. The size of local conductive pathways was assumed constant during each pulse and was updated at the beginning of the next pulse to account for the changes in electric field distribution due to the local conductive pathway expansion. Although local conductive pathway density increases with the pulse amplitude, the exact relationship is not known. Thus, we modelled two different local conductive pathway densities, $4 / \mathrm{mm}^{2}$ and $8 / \mathrm{mm}^{2}$, which lie near the low and the high end of the range of reported local conductive pathway densities $\left(3-9 / \mathrm{mm}^{2}\right)$ in the literature [35].

The contact electrodes were modelled as two cylinders with the diameter of $2 \mathrm{~mm}$ and center-to-center distance of $4 \mathrm{~mm}$. Conductive gel (Eko Gel, Italy) with the conductivity of 0.155 $\mathrm{S} / \mathrm{m}$ [37] was introduced in the model as a $2 \mathrm{~mm}$ wide layer, placed between each electrode and the skin. To limit the computational cost of numerical simulations, we reduced the size of the model along the electrodes to $1 \mathrm{~mm}$ (Fig. 1).

The electric field distribution was calculated by solving the Laplace equation:

$$
\nabla \cdot(\sigma(E) \nabla \varphi)
$$

where $\sigma$ is the electrical conductivity and $\mathrm{V}$ is the electric potential. The boundary conditions were as follows: one of the electrodes was set to ground $(\varphi=0 \mathrm{~V})$, while the other electrode was set to electric potential equal to the applied voltage. All outer boundaries of the geometry were treated as electrically insulated. Static electric field distribution was then used to calculate the resistive heat generated during the delivery of the pulses. Resistive heating was included as a source term in the Pennes' bioheat equation, which by neglecting the contribution of metabolism and blood flow [35] simplifies to: 


$$
\rho c \frac{\partial T}{\partial t}=\nabla \cdot(k \nabla T)+\sigma|\nabla \varphi|^{2},
$$

where $\rho$ and $c$ are mass density and specific heat capacity of the material, respectively, $\mathrm{T}$ is the temperature and $k$ is the thermal conductivity of the material. Before electrodes were placed on the skin, the temperature of the skin tissue was assumed to be $37^{\circ} \mathrm{C}$, whereas the temperature of the electrodes and gel was assumed to be $22^{\circ} \mathrm{C}$. Since pulse delivery does not begin immediately after placing electrodes on the skin, we first calculated the temperature distribution, established after $30 \mathrm{~s}$ of the contact between electrodes, gel and skin tissue (Supp. Fig. 2). This temperature distribution was then used as initial condition at the beginning of the first pulse. A convective heat flux boundary condition was applied at the electrode and tissue top faces, representing the heat dissipation into surrounding air with the temperature of $22^{\circ} \mathrm{C}$. The heat transfer coefficient was $5 \mathrm{~W} /\left(\mathrm{m}^{2} \mathrm{~K}\right)$. Remaining faces of electrodes and skin tissue were treated as thermally insulated.

\section{2) Gene electrotransfer}

Modelling of gene transfection efficacy did not involve computationally demanding thermal stress analysis based on the Arrhenius' law, which allowed us to increase the size of the geometry of the model. The length of cylinders representing the two electrodes, was increased to $10 \mathrm{~mm}$, the complete length of the electrodes used in experiments. Correspondingly, the size of the skin volume was extended to $14 \mathrm{~mm}$ in the direction parallel to the electrodes (Fig. 1C). An ellipsoid with the volume of $25 \mathrm{~mm}^{3}$ was placed in the middle of the dermis, representing the intradermally injected plasmid volume (Fig. 1C). Due to the size of ellipsoid and to reduce the effect of boundary, the thickness of subcutaneous layer was increased to $4 \mathrm{~mm}$. The conductivity of the plasmid solution was set to 1.4 $\mathrm{S} / \mathrm{m}$ [38], [39] and the local conductive pathway density was set to $4 / \mathrm{mm}^{2}$.

TABLE II

DEFINITION OF SKIN MODEL: GEOMETRY, ELECTRICAL AND THERMAL PROPERTIES

\begin{tabular}{|l|l|l|l|l|l|}
\hline & $\begin{array}{l}\text { Thickn } \\
\text { ess } \\
{[\mu \mathrm{m}]}\end{array}$ & $\begin{array}{l}\text { Electrical } \\
\text { conductivit } \\
\mathrm{y}[\mathrm{S} / \mathrm{m}]\end{array}$ & $\begin{array}{l}\text { Density } \\
{\left[\mathrm{kg} / \mathrm{m}^{3}\right]}\end{array}$ & $\begin{array}{l}\text { Thermal } \\
\text { conductiv } \\
\text { ity } \\
{[\mathrm{W} / \mathrm{mK}]}\end{array}$ & $\begin{array}{l}\text { Heat } \\
\text { capacity } \\
{[\mathrm{J} / \mathrm{kgK}]}\end{array}$ \\
\hline $\begin{array}{l}\text { Local } \\
\text { conductive } \\
\text { pathways }\end{array}$ & 5 & 0.1 & 1400 & 0.2 & 3600 \\
\hline $\begin{array}{l}\text { Stratum } \\
\text { Corneum }\end{array}$ & 5 & 0.0001 & 1400 & 0.2 & 3600 \\
\hline Epidermis & 15 & $0.2-0.8^{*}$ & 1200 & 0.24 & 3600 \\
\hline Dermis & 200 & $0.2-0.8^{*}$ & 1200 & 0.45 & 3300 \\
\hline $\begin{array}{l}\text { Adipose } \\
\text { tissue }\end{array}$ & 150 & $0.05-0.2^{*}$ & 900 & 0.19 & 2400 \\
\hline $\begin{array}{l}\text { Muscle } \\
\text { tissue }\end{array}$ & 90 & 0.5 & 1040 & 0.5 & 3350 \\
\hline $\begin{array}{l}\text { Subcutane- } \\
\text { ous tissue }\end{array}$ & 2000 & 0.05 & 900 & 0.19 & 2400 \\
\hline
\end{tabular}

*nonpermeabilized - fully permeabilized tissue

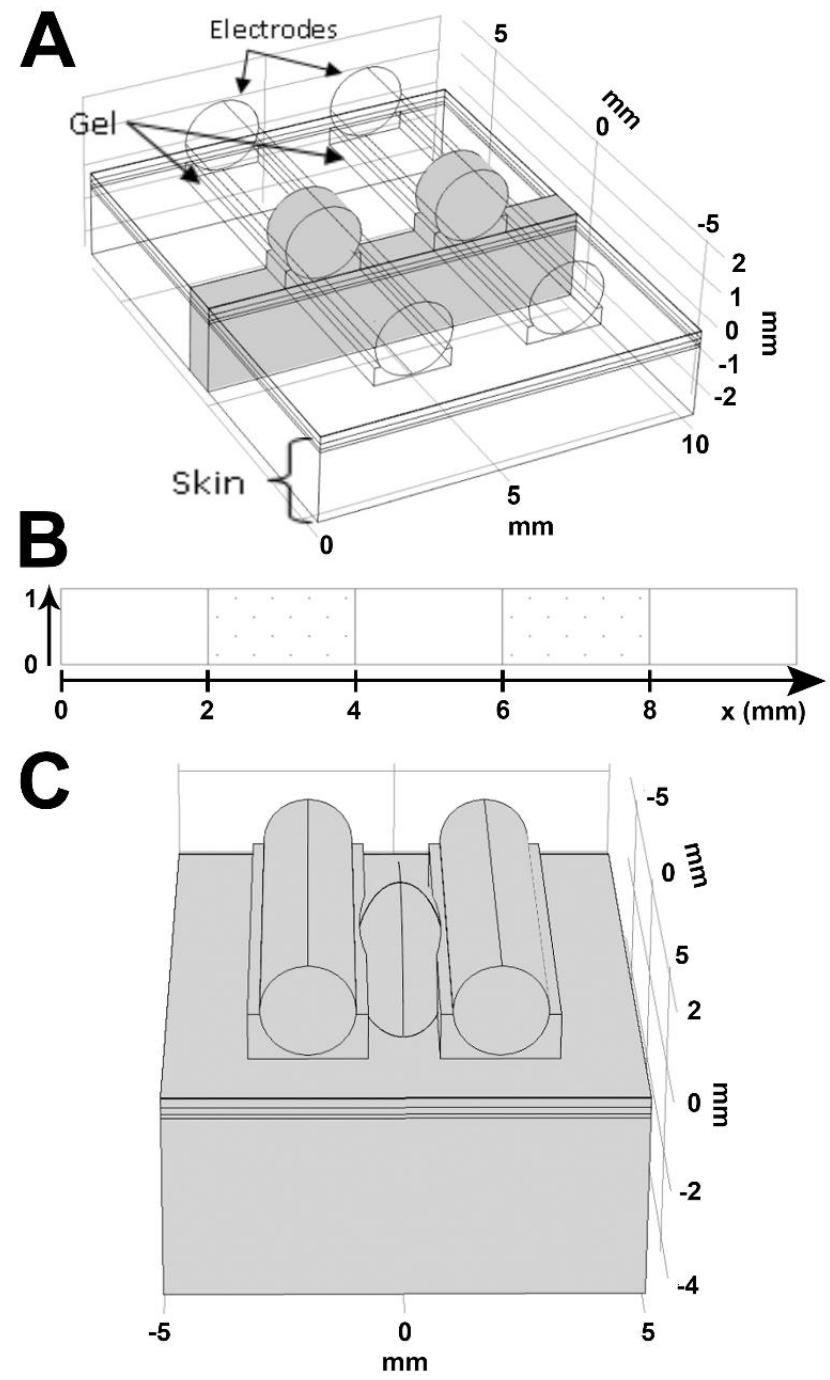

Fig. 1. Geometries used in numerical modelling. In A) and B) the geometry used in numerical modelling of heat shock response and subsequent bioluminescence emission. A) 3D geometry representing layered structure of mouse skin tissue together with the electrodes and the layer of conductive gel. The size of the subcutaneous tissue layer was increased to reduce the influence of the bottom boundary. Small size of the local conductive pathways (the initial diameter is $10 \mu \mathrm{m}$ ) and the thin layer of the stratum corneum $(5 \mu \mathrm{m})$ require very fine meshing, thus making the simulations computationally demanding. To make simulations feasible, the size of the geometry was reduced to $1 \mathrm{~mm}$ thick slice (gray), which was found to be a good compromise between computational efficacy and accuracy of results. B) Top view on the stratum corneum showing local conductive pathways with the density of $8 / \mathrm{mm}^{2}$. In C) geometry used in numerical modelling of gene expression. The intradermally injected plasmid volume is represented by an ellipsoid with the volume of $25 \mathrm{~mm}^{3}$, placed in the middle of the dermis and between the electrodes. Electrodes were in contact with the skin through the gel. In the areas where the gel was in contact with the skin, the local conductive pathways were distributed throughout the stratum courneum with the density of 4 local conductive pathways $/ \mathrm{mm}^{2}$.

3) Electroporation of the skin

Five different pulse protocols were used in experiments: HV, EGT, MV, HV + MV unipolar and HV + MV bipolar (Table I, Supp Fig 1). The duration and number of electric pulses determine the threshold for EP. In general, shorter pulses require higher electric field amplitudes to achieve the same level of EP [40]. Despite this straightforward relationship, EP threshold proved to be rather complex function of pulse 
amplitude, width and number of pulses. In the literature, we only found the data on EP thresholds for HV pulse protocol. The reversible and irreversible thresholds were set to $600 \mathrm{~V} / \mathrm{cm}$ and $1200 \mathrm{~V} / \mathrm{cm}$ [33], respectively. We reduced both thresholds for $5 \mathrm{~ms}$ (EGT protocol) and $20 \mathrm{~ms}$ pulses (MV protocol) to 1.8- and 2.5-times lower values, respectively, according to Pucihar et al. [41]. The increase in electrical conductivity observed at local electric fields above the reversible threshold, was represented in the model through the sigmoid curve. The temperature dependency of electrical conductivity was neglected, since it is negligible compared to the conductivity changes due to EP. All properties of the skin tissue used in the model are given in Table II.

\section{4) Arrhenius relationship}

Arrhenius relationship was used to determine cell death due to excessive thermal damage [42] and to predict the bioluminescent intensity associated with each of the pulse protocols:

$$
\Omega=\int_{0}^{t} A \exp \left(-\frac{E_{a}}{R T}\right) d \tau
$$

where $\Omega$ indicates the damage factor, A the frequency factor ( $\mathrm{s}$ $\left.{ }^{1}\right)$ and Ea the activation energy $(\mathrm{J} / \mathrm{mol})$. The first set of Arrhenius parameters, describing the thermal damage, was taken from the literature [24], [43], while the second set of parameters, regarding HSP expression, was determined from the mice in the control group (Fig. 2C, Fig. 3). More precisely, it was determined from the bioluminescence intensity measurements resulting from 8 minutes long exposures to constant-temperature water baths. When the temperature is constant, the damage factor, or in our case the bioluminescence intensity, becomes a linear function of heating time. Therefore, both Arrhenius parameters can be determined from the linear regression of $\ln (t)-\ln (\Omega)$ versus $1 / T$.

\section{5) Numerical simulations of bioluminescence intensity}

Excessive cellular stress can cause irreparable damage to the structures involved in the protein synthesis, resulting in reduced bioluminescence intensity. In fact, it has been shown that when the cell-surviving fraction following a thermal stress is below 0.4 , even the surviving cells are unable to produce HSP's [23], [44]. To account for the reduced HSP production due to local thermal damage, we multiplied the bioluminescence intensity with local cell surviving fraction. If the local thermal damage was so severe that cell-surviving fraction dropped below 0.4 , bioluminescence intensity was set to zero. Further, the cells experiencing irreversible EP are also unable to express HSP's and emit any light. Therefore, the bioluminescence intensity inside the volume of irreversible EP was also set to zero. Finally, cells can only emit a limited amount of light due to the expression of HSP's. Therefore, we implemented the restriction on the maximum bioluminescence intensity, which was determined from the heating protocol of 40 minutes at $44^{\circ} \mathrm{C}$. This heating protocol, namely, was shown to result in maximum HSP expression in an in vitro study [23].

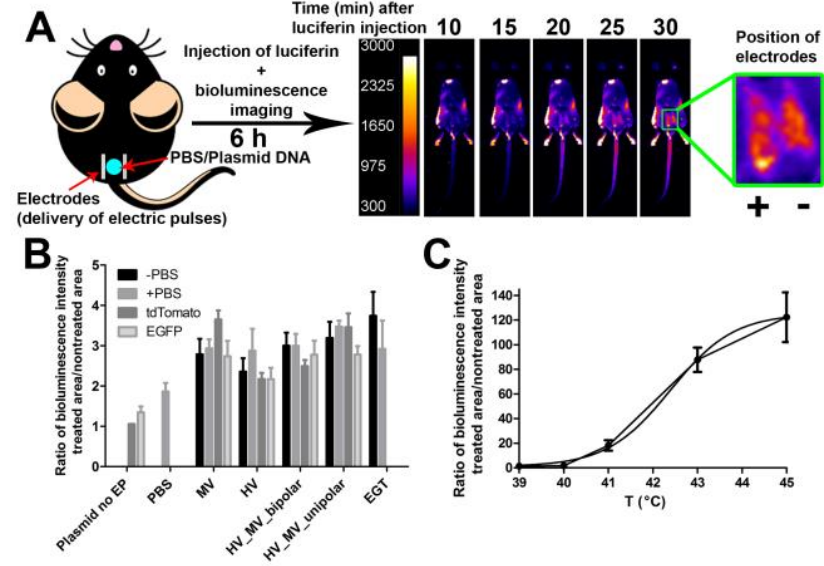

Fig. 2. Electroporation induces bioluminescence in Hspalb-LucF $(+/+)$ Hspalb-mPlum (+/+) mice. Experimental design in (A): Double transgenic mice Hspalb-LucF (+/+) Hspalb-mPlum (+/+) were injected with PBS/plasmid DNA immediately before EP and bioluminescence $6 \mathrm{~h}$ after EP due to the expression of Hspalb-LucF after the injection of luciferin was imaged. Green square shows a magnified image of the bioluminescence directly under the position of electrodes. Representative heat map images of bioluminescence $6 \mathrm{~h}$ after EP are shown (scale on the left side). The + and - denote the position of anode and cathode, respectively. In (B) the ratio of bioluminescence intensity in treated vs nontreated area is shown for groups receiving either no injection (-PBS), vehicle (PBS), vehicle and tdTomato plasmid DNA (tdTomato), vehicle and EGFP plasmid DNA (EGFP) and receiving either one of the EP pulse parameters (x axis, Table I) or no EP (x axis; Plasmid no EP, PBS). The ratio of bioluminescence intensity in treated vs non-treated area is shown for the control group (C), i.e. $8 \mathrm{~min}$ in water bath at designated temperatures with superimposed non-linear fit (sigmoidal dose-response curve). Data represents mean values \pm SEM.

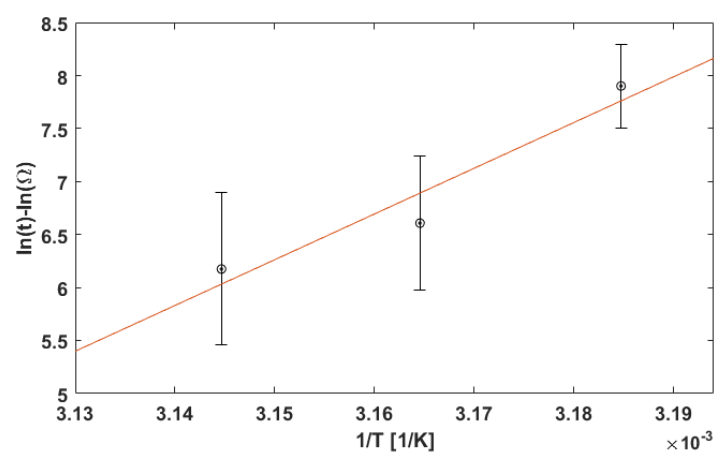

Fig. 3. Bioluminescence signal increase determined $6 \mathrm{~h}$ after the exposure to constant-temperature water bath follows the Arrhenius relationship. The solid line is a linear fit of the three data points, which was used to determine the Arrhenius parameters describing the expression of LucF resulting in the measured increase in the bioluminescence signal.

\section{6) Light propagation}

Bioluminescence light is very suitable for in vivo applications, since large portion of its broad emission spectrum lies above $600 \mathrm{~nm}$, with an emission peak at $612 \mathrm{~nm}$ at $37^{\circ} \mathrm{C}$ [45]. Below $600 \mathrm{~nm}$, namely, strong haemoglobin absorption limits the transmission of light through the tissue [46]. Scattering, on the other hand, is less wavelength-dependent and limits the spatial resolution of bioluminescence images. In the highly scattering media, such as skin tissue, where scattering dominates over absorption, a diffusion approximation can be 
used to model the light propagation:

$$
\begin{gathered}
-\nabla \cdot(D(r) \nabla \Phi(r))+\mu_{a} \Phi(r)=S(r), \quad r \in \Omega \\
\Phi(r)+2 A(r) D(r) \hat{n} \cdot \nabla \Phi(r)=0, \quad r \in \partial \Omega
\end{gathered}
$$

$D$ and $\mu_{a}$ represent the diffusion and absorption coefficient, respectively. $\Phi(r)$ denotes photon power density, $S(r)$ denotes the source distribution and $A$ denotes a factor accounting for the difference in refractive indices across the boundary. The diffusion coefficient is given by $D=1 /\left(3\left(\mu_{a}+\mu_{s}^{\prime}\right)\right)$, where $\mu_{s}^{\prime}$ is the reduced scattering coefficient. Both optical parameters, absorption and reduced scattering coefficient for the mouse skin tissue were taken from the literature [32].

\section{7) Gene expression}

GET is a complex multistep process, which requires the presence of plasmid DNA in the immediate vicinity of reversibly electroporated cell membrane [47]. In addition to increasing the cell membrane permeability, electric pulses also bring DNA molecules in close contact with the membrane due to electrophoresis. Electrophoretic force namely drags the negatively charged DNA molecules toward the side of the cell membrane facing the cathode. The distance that DNA molecules travel due to electrophoresis [48] can be expressed by:

$$
L=\mu E t
$$

where $\mu$ represents electrophoretic mobility, $E$ electric field and $t$ the duration of electric pulses. The electrophoretic mobility of EGFP with $4.7 \mathrm{kbp}\left(\mu=1.5 \times 10^{4} \mu \mathrm{m}^{2} / \mathrm{Vs}\right)$ was taken from the literature [48]. Since electrophoretic mobility increases linearly with the length of the plasmid, we set the electrophoretic mobility of tdTomato plasmid with $5.4 \mathrm{kbp}$ to $\mu=1.73 \times 10^{4}$ $\mu \mathrm{m}^{2} / \mathrm{Vs}$.

In order to evaluate three pulse protocols (HV, MV, HV-MV) in terms of their relative transfection efficiencies, we compared the number of particles inside the volume of reversible EP. Since the volume of reversible as well irreversible EP increases with local conductive pathway expansion, we used electric field distribution resulting from the last pulse to determine the volume of reversibly electroporated cells. For practical reasons and due to limitations of the software, the same electric field distribution was used to simulate the trajectories of charged particles representing plasmid DNA. In the case of HV-MV protocol, the determination of reversible EP volume was based on the last HV pulse, whereas electrophoretic movement simulation was based on the last MV pulse. The simulation of electrophoretic movement was performed using the Charged particle tracing module provided by Comsol. The same number of charged particles was released uniformly from the surface of the bleb every $1 \mathrm{~ms}$ to simulate continuous flux of DNA molecules from the bleb to the skin tissue during the pulse delivery. The number of simulated charged particles was chosen arbitrarily, however, it was large enough to obtain accurate estimates of relative transfection efficiencies. The time of simulation was equal to complete duration of electric pulses (0.8 ms, $160 \mathrm{~ms}$ and $80 \mathrm{~ms}$ for HV, MV and HV-MV pulse protocol, respectively). Numerical simulations were performed in Comsol Multiphysics ${ }^{\circledR}$ (v5.3, Stockholm, Sweden), except for thermal damage calculation, which was performed in Matlab ${ }^{\circledR}$ (R2017a; The MathWorks, Inc., Natick, MA, USA). The time dependent temperature distribution from the model was imported into Matlab using the Comsol's Livelink with Matlab feature. We used physics-controlled mesh with finer or fine element size for thin layers (stratum corneum with local conductive pathways, epidermis and dermis) and normal element size elsewhere.

\section{8) Statistical analysis}

Statistical analysis was carried out using Prism 5 Statistical software (GraphPad Software Inc). A Shapiro-Wilk normality test was used and followed by One-way ANOVA with Tukey's test or Pearson test (correlation analysis) were used. A value of $p<0.05$ was considered to represent a significant difference between groups. Data represents mean \pm SEM unless specified otherwise.

\section{RESULTS}

A. Electroporation induces expression of Hspalb-dependent LucF resulting in bioluminescence signal

To determine the level of stress/HSP expression due to EP, we used transgenic Hspalb-LucF (+/+) Hspalb-mPlum (+/+) mice [21], [22]. The exposure of mice to external stress (heat) results in expression of LucF due to activation of Hspalb promoter, which can be measured as a bioluminescence signal due to luciferase activity of LucF after injection of luciferin and in expression of mPlum protein which can be measured by its emitted fluorescence signal. Bioluminescence signal under the position of electrodes could be readily detected $6 \mathrm{~h}$ after EP (Fig. 2A), in contrast, we were unable to detect mPlum fluorescence signal at any time point after EP, most likely due to low levels of expression (data not shown). Quantification of the bioluminescence signal intensity showed that EP, regardless of the electric pulse parameters used increased mean bioluminescence up to 4 fold compared to the baseline bioluminescence signal of the non-exposed skin (Fig. 2B). There was no statistical difference in the bioluminescence intensities after EP between the different electric pulse parameters that we used in the study. To characterize our transgenic mouse model, we exposed the right back leg of mice to a constant temperature ( $8 \mathrm{~min}$ in a water bath) and performed the same bioluminescence imaging as for EP treated mice (Fig. 2C). Exposure of the leg for $8 \mathrm{~min}$ to $41^{\circ} \mathrm{C}$ resulted in a 20 -fold increase in mean bioluminescence compared to the baseline bioluminescence signal of the non-exposed part of the mouse and higher temperatures resulted in even higher increase in mean bioluminescence, showing a temperature dependency of the bioluminescence signal. Altogether, this shows that EP induced bioluminescence can be detected in the transgenic Hspalb-LucF (+/+) Hspalb-mPlum (+/+) mice, however, the overall increase of the bioluminescence signal is low compared to the induction achieved by exposing the leg of mice for $8 \mathrm{~min}$ to an increased temperature. Of interest it is to note, that even though the detected increase in bioluminescence signal was low 
compared to the positive control ( 8 min heating at $45^{\circ} \mathrm{C}$ ), it was achieved in a very short time, which is 6000 to 600000 shorter than total electric pulse duration (from $80 \mathrm{~ms}$ to $800 \mu \mathrm{s}$ ).

B. Numerical modelling of electroporation induced bioluminescence signal due to the expression of Hspalb-LucF

To better understand how EP can in a such a short time induces the activation of Hspalb and subsequent expression of LucF resulting in the measured increase in the bioluminescence signal (Fig. 2) and the spatial relationship between the position of the electrodes and the induction of Hspalb-LucF (Fig. 2A), we employed numerical modelling.

First, we determined the relationship between bioluminescence signal intensity and temperature from our positive control group (Fig. 2C). As the first temperature protocol resulting in an elevated bioluminescence signal was 8 min exposure to $41^{\circ} \mathrm{C}$, we therefore performed linear fitting on three data points, corresponding to $41^{\circ} \mathrm{C}, 43^{\circ} \mathrm{C}$ and $45^{\circ} \mathrm{C}$ (Fig. 3). The correlation coefficient of 0.93 suggests that bioluminescence intensity follows Arrhenius relationship in the temperature range of $41^{\circ} \mathrm{C}$ $-45^{\circ} \mathrm{C}$. The frequency factor and activation energy, obtained from linear regression analysis are $2.39 \times 10^{56} \mathrm{~s}^{-1}$ and 359 $\mathrm{kJ} / \mathrm{mol}$, respectively. These parameters were then used in numerical model.

All of the tested EP protocols (HV, EGT, MV, HV-MV uni, HV-MV bi) resulted in a very low bioluminescence signal intensities, achieving only up to 4-fold increase in the signal from the treated area with respect to the background (Fig. 2B, Fig. 4). Compared to the positive control group, EP-induced bioluminescence signal equals up to $25 \%$ of the bioluminescence signal resulting from the $8 \mathrm{~min}$ exposure to $41^{\circ} \mathrm{C}$, the threshold temperature for thermal stress response activation. However, since bioluminescence images actually show the mean intensity within each pixel, we cannot conclude there was no local hyperthermia. On the contrary, our simulations show that all pulse protocols caused the thermal expansion of local conductive pathways (Fig. 4). The EGT pulse protocol shows the largest local conductive pathway expansion $(180 \mu \mathrm{m}$ in diameter at the density 4 local conductive pathways $/ \mathrm{mm}^{2}$ ). Other protocols resulted in significantly smaller local conductive pathway expansion (up to $55 \mu \mathrm{m}$ in diameter) either due to short duration or due to low amplitude of the pulses.

As we can observe from our model (Fig. 4A, B), the size of the local conductive pathways increases in the direction towards the other electrode. The volume of thermally damaged cells lies beneath the local conductive pathways and increases with the size of local conductive pathways, as expected. Nevertheless, the decrease of bioluminescence signal due to thermal damage is only minor, since the affected volume is rather small. Moreover, the volume of thermal damage lies within much larger volume of irreversible EP (Fig. 4C), which is therefore the main factor affecting the bioluminescence signal.

If we take a closer look on the distribution of the bioluminescence, we can observe that the bioluminescence signal originates from the round-shaped volume of epidermal cells, lying around the volume of irreversible EP (Fig. 4D). It turns out, namely, that only the cells lying close to the volume of irreversible EP are exposed to sufficiently high temperatures to induce the activation of Hspalb and subsequent expression of LucF.

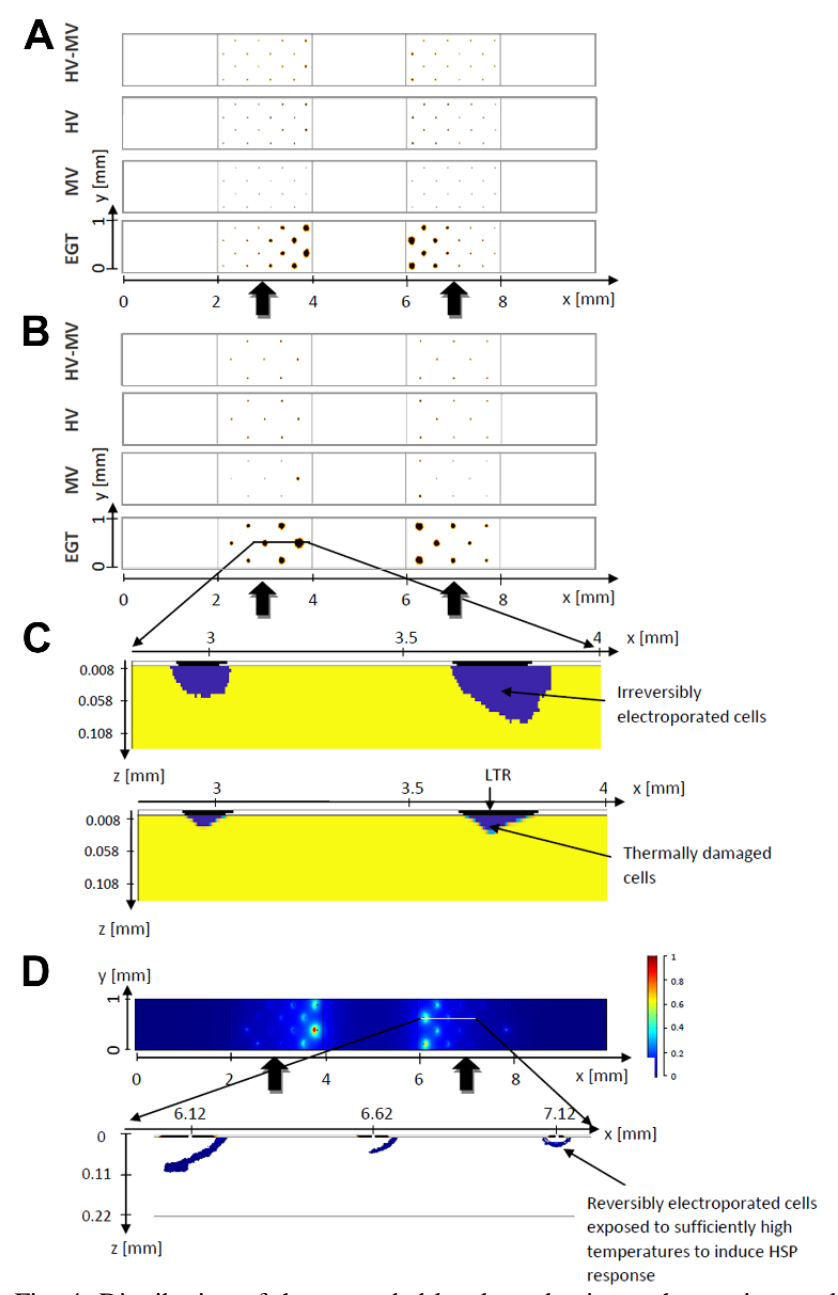

Fig. 4. Distribution of the expanded local conductive pathway sizes and position of cells emitting bioluminescence signal after the last pulse. The distribution of the expanded local conductive pathway sizes at the surface of the stratum corneum after the last pulse for HV-MV, HV, MV and EGT pulse parameters for 2 different pre-pulse local conductive pathway densities, (A) 8 local conductive pathways $/ \mathrm{mm}^{2}$ and (B) 4 local conductive pathways $/ \mathrm{mm}^{2}$. Pre-pulse local conductive pathways with diameter of 10 $\mu \mathrm{m}$ were uniformly distributed throughout the volume of stratum corneum lying directly beneath the gel (areas between $2-4 \mathrm{~mm}$ and $6-8 \mathrm{~mm}$ ). (C) The volume of cells not being able to emit light due to irreversible EP (above) is much larger than volume of thermally damaged cells (below). In (D) the distribution of cells contributing to the bioluminescence signal after EGT pulse protocol (below). These cells lie far enough from the center of the local conductive pathways to avoid irreversible EP yet close enough to induce the thermal response. Corresponding distribution of the bioluminescence signal intensity at the surface of the stratum corneum (above). The arrows indicate the central position of electrodes. HV-MV denotes both, unipolar and bipolar protocols, since they show no difference in terms of thermal response.

According to numerical model results, the density of 4 local conductive pathways $/ \mathrm{mm}^{2}$ shows similar bioluminescence intensities for all pulse protocols (Fig. 5A). The density of 8 local conductive pathways $/ \mathrm{mm}^{2}$, on the other hand, shows the highest bioluminescence intensity for EGT pulse protocol, followed by HV-MV, MV and HV protocols, respectively (Fig. 
5B), which is in line with experiments. A good agreement can also be observed in terms of the shape of the profiles, showing two distinctive peaks (Fig. 5A, B). However, the fraction of light-emitting cells is very small, at most $1 \%$ of all epidermal cells (EGT pulse protocol, 8 local conductive pathways $/ \mathrm{mm}^{2}$ ). Therefore, considering that light-emitting cells experienced mild thermal stress, we can stipulate that local hyperthermia alone cannot explain the EP induced bioluminescence.

A

B

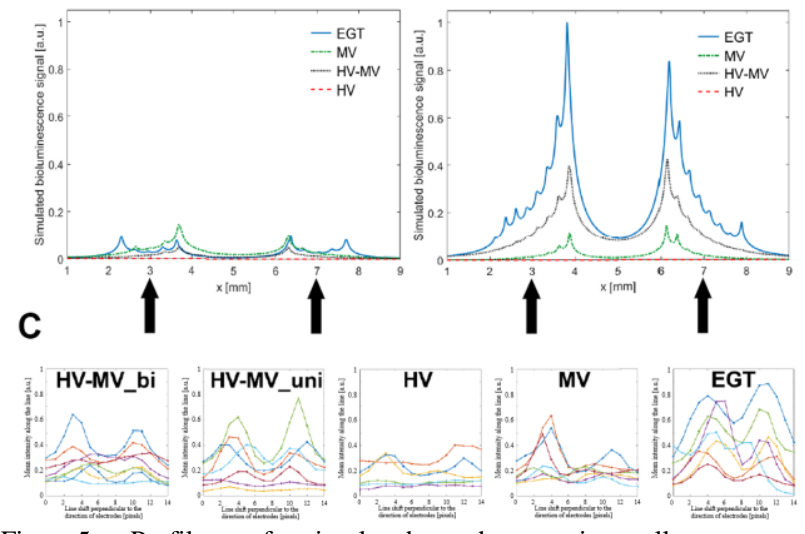

Fig. 5. Profiles of simulated and experimentally measured bioluminescence intensities corresponding to different pulse protocols. Profiles of simulated bioluminescence intensities, resulting from the thermal stress at the local conductive pathway density of 4 local conductive pathways $/ \mathrm{mm}^{2}$ (A) and 8 local conductive pathways $/ \mathrm{mm}^{2}$ (B) as predicted by numerical model. HV+MV denotes both, unipolar and bipolar protocols, since they show no difference in terms of thermal stress levels. Position of the electrodes position is indicated by arrows. Profiles of experimentally measured bioluminescence intensities corresponding to different pulse protocols (C). Each curve shows the average profile of an individual mouse. Each data point on the curve represents the average intensity along the line, parallel to the electrodes, which was shifted from the beginning to the end of the region of interest (ROI).

\section{Efficacy of GET of EGFP and tdTomato plasmid DNA depends on the pulse parameters}

EP can be successfully used to deliver plasmid DNA into cells and tissue, thus inducing the expression of genes of interest [9]. However, the efficacy of GET varies with pulse parameters used and with the target organ [49]. To determine whether the efficacy of GET to skin can be improved and whether there is a correlation between EP induced heat shock response and subsequent gene expression we used two different plasmids, one coding for EGFP and the other for tdTomato, both under constitutive CMV promoter, and measured their expression after GET. Due to the EGT pulses being primarily used for gene transfer to tumours, we did not use them in subsequent experiments involving gene expression after GET to skin [16], [26].

Out of the four tested electric pulse protocols (HV, MV, HVMV uni and HV-MV bi) the highest expression of EGFP and tdTomato was achieved with both HV-MV protocols (Fig. 6), with no statistically significant difference between them, thus demonstrating that reversing the polarity of electric pulses within the train of pulses does not improve GET efficacy in vivo in skin. Interestingly, the MV electric pulse protocol proved as efficient as the HV-MV protocols in the group of mice where EGFP plasmid DNA was used (Fig. 6B), whereas in the group of mice where tdTomato plasmid DNA was used its efficacy was only about $50 \%$ of the HV-MV pulse protocols (Fig. 6A). To note, is that in both cases the HV pulse parameters were able to induce only low levels of gene expression regardless of the plasmid DNA used (Fig. 6).
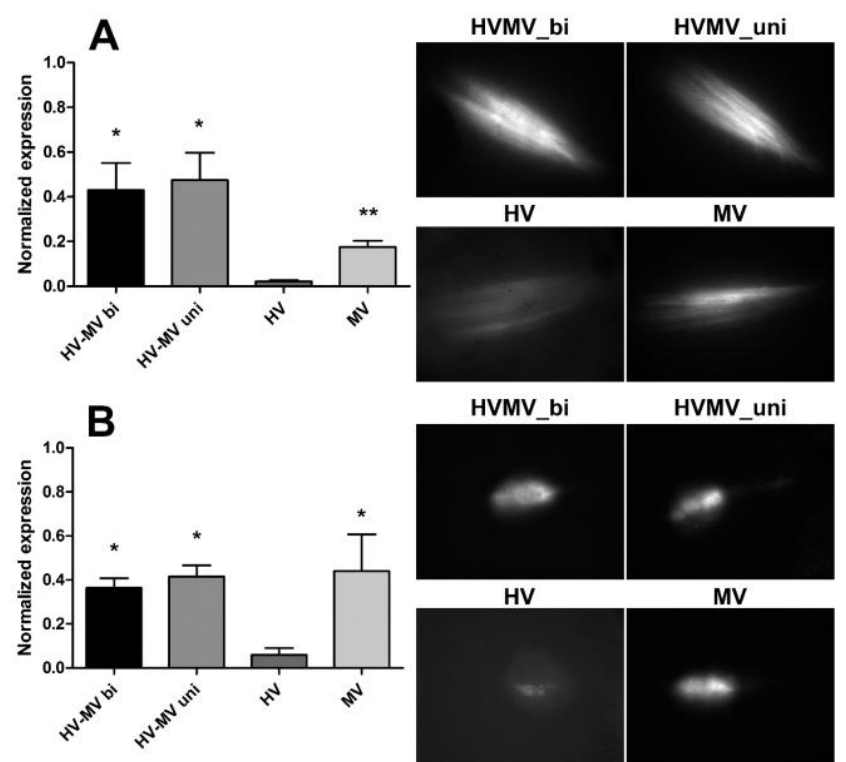

Fig. 6. Expression of EGFP and tdTomato after gene electrotransfer with different electric pulse parameters. Double transgenic mice Hspalb-LucF $(+/+)$ Hspalb-mPlum (+/+) were injected with plasmid DNA immediately before EP and the expression of tdTomato (A) and EGFP (B) was imaged daily with a fluorescence macroscope and quantified as a fraction of the maximum mean fluorescence intensity signal of all the mice in the entire imaging period (A and B). The representative fluorescent images of tdTomato and EGFP expression taken 14 days after transfection are shown. The contrast on the images was adjusted to correct for the use of ND filters and the large differences in fluorescence intensity between different electric pulse parameters. Data represents mean values \pm SEM. In (A) * $\mathrm{P}<0.05$ compared to $\mathrm{HV}$ and $\mathrm{MV}, * * \mathrm{P}<0.05$ compared to HV. In (B) * $\mathrm{P}<0.05$ compared to HV.

Our results on Hspalb-LucF induction after EP suggest that the skin directly under the electrodes should also have the highest level of gene expression after GET of plasmid DNA. The fluorescence intensity profiles (indicating the level of expression) of EGFP and tdTomato measured 1 day after EP (Fig. 7) showed a remarkable similarity to the experimentally measured bioluminescence intensities (Fig. 2 and Fig. 5) with the majority of expression detected under the electrodes, with a more pronounced peak under the anode except when HV pulse protocol was used to deliver tdTomato plasmid DNA (Fig. 7). The injection of plasmid DNA without EP resulted in barely detectable expression of either EGFP or tdTomato (Fig. 7) demonstrating the need for EP to enable plasmid DNA to enter the cells. Although the similarity between the measured fluorescence intensity profiles of EGFP and tdTomato expression and bioluminescence signal would suggest a strong correlation between the Hspa1b-LucF induction after EP and GET efficacy, our results did not confirm this. We were only able to detect a modest correlation (Pearson $\mathrm{r}=0.401, \mathrm{P}=0.047$ ) between the expression levels of tdTomato and bioluminescence signal resulting from Hspalb-LucF induction after EP, whereas there was no correlation in the group where EGFP plasmid DNA was used (Fig. 8). A possible explanation 
could be found in the localization of expression of tdTomato and EGFP at later time points after EP (Fig. 6) where the expression was no longer localized only under the electrodes, but more homogeneously in the entire electroporated area of the skin and in the muscle fibres under the skin (Fig. 6A), indicating that, although the initial expression is observed mainly under the electrodes, there is a large volume of cells between the electrodes that is also transfected with plasmid DNA.

All together, these results show that HV-MV electric pulse protocols, with or without reversing the polarity of pulses, can achieve higher levels of expression compared to MV and HV electric pulse protocols, however, their efficacy also depends on the plasmid DNA used. Although, the initial expression of fluorescent proteins resembles the pattern of LucF induction after EP, the overall expression of the gene of interest is not correlated with the level of LucF induction.

\section{Numerical modelling of GET efficacy}

To further explore the relationship between electric field distribution and gene expression due to introduction of plasmid DNA, after EP, we once again used numerical modelling. The presence of a plasmid volume affects the electric field distribution resulting in higher temperatures and larger local conductive pathway expansion (Fig. 9) compared to bioluminescence experiments with no plasmid injection. Despite higher temperatures, thermal damage was not evaluated, since it overlaps with larger volume of irreversible $\mathrm{EP}$, as shown in the case of bioluminescence. Right column of the Fig. 9 shows the side of the bleb facing the anode. Electrophoretic movement towards the cathode is negligible, thus explaining the pronounced peak of expression under the anode, observed in experiments.
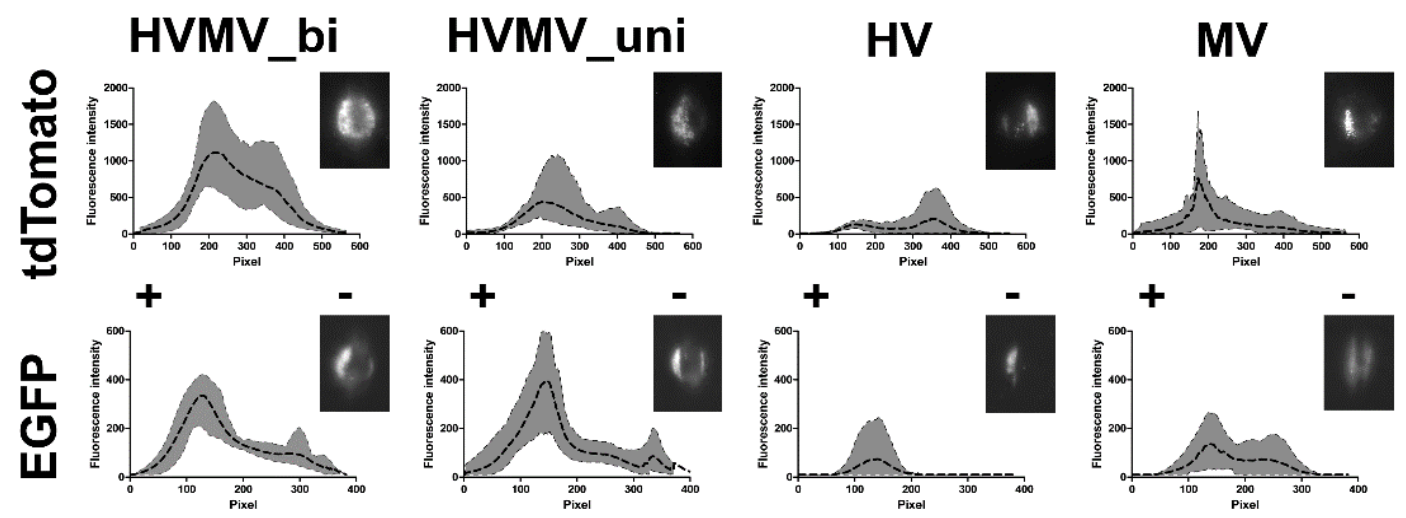

\section{Plasmid}

Fig. 7. Fluorescence intensity profiles of tdTomato and EGFP after gene electrotransfer. Double transgenic mice Hspalb-LucF (+/+) Hspa1b-mPlum (+/+) were injected with plasmid DNA immediately before EP and the fluorescence intensity profiles 1 day after gene electrotransfer of tdTomato (top panel) and EGFP (bottom panel) were determined from images (inserts) obtained with a fluorescent stereomicroscope and quantified as mean pixel intensity on a 400 pixel thick line. 4 different electric pulse parameters were used (HV-MV bi, HV-MV uni, HV and MV). The + and - signs denote the position of anode and cathode, respectively. Data are presented as mean fluorescent intensity at each pixel (thick dashed lines) and the range (grey area between thin dashed lines) for each pixel on the line.
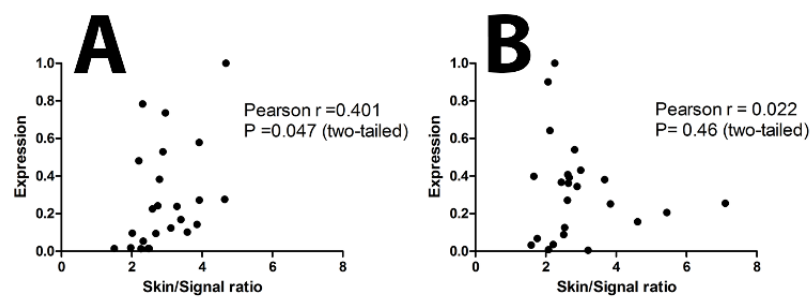

Fig. 8. Correlation of the expression of tdTomato or EGFP 14 days after transfection and bioluminescence signal intensity. Correlation plot of the ratio of bioluminescence intensity in treated vs non-treated area ( $\mathrm{x}$ axis) vs relative maximum expression (y axis) for tdTomato (A) and EGFP (B). Double transgenic mice Hspalb-LucF (+/+) Hspalb-mPlum (+/+) were injected with plasmid DNA immediately before EP and the bioluminescence $6 \mathrm{~h}$ after EP due to the expression of Hspalb-LucF after the injection of luciferin was imaged. The expression of tdTomato (A) and EGFP (B) was quantified as a fraction of the maximum mean fluorescence intensity signal of all the mice in the entire imaging period. Pearson $r$ correlation, $\mathrm{P}<0.05$ was considered statistically significant.

Gene transfection efficiencies of the three pulse protocols used in experiments were evaluated in terms of the number of plasmid DNA molecules inside the volume of reversible EP. After the completion of the pulse delivery, the lowest number of plasmid DNA molecules present inside the volume of reversible EP was obtained in the case of $\mathrm{HV}$ pulse protocol
(Table III), which agrees with experiments. MV pulses, on the contrary, achieve better transfection efficacy due to larger electrophoretic distance. According to our numerical model, even better transfection efficacy is expected from the combination of $4 \mathrm{HV}$ and $4 \mathrm{MV}$ pulses, although plasmid DNA travels only about half a distance compared to MV protocol. The use of HV pulses, namely, results in larger volume of reversible EP, particularly in combination with longer pulses, which cause larger thermal expansion of local conductive pathways. However, with larger local conductive pathways increases also the volume of irreversible EP, which prevents successful transfection. This double effect is clearly visible from the Fig. 9, which presents the movement of plasmid DNA through the volume of reversible EP. Namely, in the region between the center of larger local conductive pathways and the surface of the bleb, only initial part of the movement is presented, meaning that only those cells, lying near the surface of the bleb contribute to the transfection efficacy. The difference in mobility of both plasmids due to their different length has only minor effect on the expected transfection efficacy. 
TABLE III

RELATIVE NUMBER OF PLASMID DNA MOLECULES PRESENT IN THE VOLUME OF REVERSIBLE EP DUE TO ELECTROPHORETIC MOVEMENT AS A MEASURE OF GENE ELECTROTRANSFER EFFICACY

\begin{tabular}{|l|l|l|l|}
\hline & HV & MV & $\begin{array}{l}\text { HV - } \\
\text { MV }\end{array}$ \\
\hline Volume of reversible EP $\left(\mathrm{mm}^{3}\right)$ & 2.58 & 1.70 & 3.29 \\
\hline $\begin{array}{l}\text { Number of EGFP }(4.7 \mathrm{kbp}) \text { plasmid DNA } \\
\text { molecules present in the volume of } \\
\text { reversible EP at the end of pulse delivery } \\
\text { normalized to HV-MV protocol }\end{array}$ & 0.14 & 0.74 & 1 \\
\hline $\begin{array}{l}\text { Number of tdTomato (5.4 kbp) plasmid } \\
\text { DNA molecules present in the volume of } \\
\text { reversible EP at the end of pulse delivery } \\
\text { normalized to HV-MV protocol }\end{array}$ & 0.14 & 0.71 & 1 \\
\hline
\end{tabular}

\section{DISCUSSION}

Optimizing pulse parameters for GET means finding a compromise between optimal electric field distribution, providing sufficient volume of reversibly electroporated cells, optimal plasmid DNA distribution and minimal tissue damage. In this study, we examined the relative importance of electroporated volume, electrophoresis, stress response and thermal damage on transfection efficacy. For this purpose, we used bioluminescence imaging and numerical modelling in addition to measuring the expression levels of two plasmids (coding for EGFP and tdTomato) after GET with different pulse protocols.

Despite the advances in computer power and software tools, skin EP remains challenging for numerical simulations. The main reasons are very fine meshing due to complexity of the skin structure and very fine time stepping, which is required to catch the rapid changes in temperature distribution during the pulse delivery. Therefore, we built only a $1 \mathrm{~mm}$ thick slice of complete geometry. Namely, we had to reduce the number of local conductive pathways, which make the simulations very time consuming, especially in combination with the thermal damage calculation. However, $1 \mathrm{~mm}$ thickness proved to be sufficient to obtain accurate results, since further increase in size did not affect the results. Thermal damage calculation was not included in GET simulations, thus the reduction of geometry was not necessary.

Numerical model shows the thermal expansion of individual local conductive pathways, which depends on the local electric field. In addition to size, the distribution of local conductive pathways also affects EP of underlying layers and electrophoretic movement of plasmid DNA. Better understanding of local conductive pathway formation is, therefore, required for improving the accuracy of simulations. We modelled local conductive pathways as predefined structures, thus neglecting any dynamics in local conductive pathway formation. Also, we assumed a uniform distribution of local conductive pathways across the part of the stratum corneum, exposed to high electric fields (below the gel). Actual distribution of local conductive pathways is probably not uniform, since their density depends on the local electric field. Nevertheless, model is still able to explain the transfection efficiencies of different pulse protocols. Moreover, model enables visualization of the volume of cells transfected with plasmid DNA. Therefore, model can be used as a tool to optimize pulse parameters and site of administration for targeted transfection of different skin layers. By regulating the depth of transfection in the skin we can, namely, achieve local or systemic action of gene and control the duration of gene expression [3].

\section{A. Bioluminescence (stress response to EP)}

Bioluminescence imaging was performed in order to evaluate the stress response to five different EP pulse protocols. All tested pulse protocols resulted in similar, low bioluminescence intensity. In order to explore the correlation between measured bioluminescence and thermal stress, we employed numerical modelling.

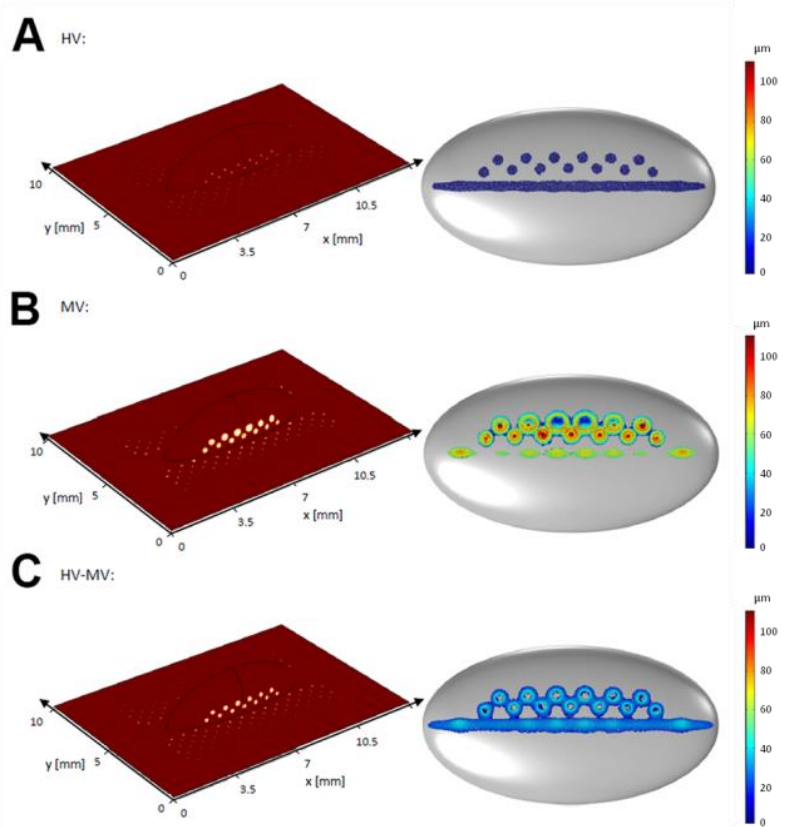

Fig. 9. Left column: Stratum corneum (red) with local conductive pathways (white) after the last pulse of A) HV, B) MV and C) HV-MV pulse protocols. The distribution of the size of local conductive pathways beneath the electrodes is symmetrical. Right column: Electrophoretic movement of EGFP (4.7 kbp) plasmid DNA through reversibly electroporated volume of the skin tissue. Presented are trajectories of the plasmid DNA movement due to nonuniform electric field resulting from A) HV, B) MV and C) HV-MV pulse protocols inside the volume of reversible EP. Gray ellipsoid represents the injected volume of plasmid DNA (bleb). The colors of trajectories represent the distance of the plasmid DNA from the surface of the bleb. The maximum electrophoretic distance by MV pulse protocol is more than $100 \mu \mathrm{m}$ meaning that plasmid DNA can travel through dermis and reach the epidermis. As we can see from the images, the majority of the volume where gene transfection is expected, lies near the edges of local conductive pathways since irreversible EP prevents successful transfection near the center of the local conductive pathways. Represented is the side of the bleb facing the anode. Electrophoretic movement in the opposite direction (toward the cathode) is negligible.

The results of numerical simulations show that the volume of cells, which are exposed to local hyperthermia and are not irreversibly electroporated, is too small to explain the measured 
bioluminescence. This indicates that bioluminescence at least partially results from the stress due to EP itself. However, considering the uncertainty in modelling assumptions and relatively large number of parameters, we could not reliably quantify the contribution of thermal and EP induced stress to bioluminescence.

First, bioluminescence intensity is affected by the uncertainty in EP threshold determination, especially the irreversible threshold, which served as an indicator of cell death [50]. Another source of uncertainty in numerical model results is the complexity of heat shock response. Bioluminescence images were acquired 6 hours after EP, since this time delay has been determined as optimal for achieving maximum bioluminescence intensity after long exposures to moderate temperatures [22]. In our case, however, hyperthermia was achieved by short exposures to high temperatures, which results in delayed bioluminescence peak. This delay was observed in vitro [51] as well as in vivo [52]- [54] and depends on the severity of the thermal stress and therefore on the time required to repair the damaged cell mechanisms. Moreover, we have to keep in mind possible limited validity of Arrhenius parameters at high temperatures, since regression analysis was performed in the temperature range from $41^{\circ} \mathrm{C}$ do $45^{\circ} \mathrm{C}$. Nevertheless, the temperature rises above $60^{\circ} \mathrm{C}$ are very limited. Also, these areas are usually too severely affected by either thermal damage or irreversible EP to emit any light. Moreover, pulse protocols used in irreversible electroporation (IRE) where much higher voltages and number of pulses are used than in our study, is still considered as a non-thermal ablation method [55].

Finally, there is a limited knowledge on the cellular stress due to EP itself, which in tissues may include anything from heat induced stress to inflammation induced stress or even temporary oxygen deprivation due to vascular lock induced by EP [18], [56], [57]. Similar observation in terms of treatment (by ultrasound) related stress was reported [51], showing increased levels of HSP even below the thermal stress threshold, presumably due to ultrasound treatment itself. Increased levels of HSP were demonstrated also in the case of EP [19], [20], indicating that the measured increased bioluminescence intensity after EP is indeed due to HSP induction.

\section{B. Gene expression of genes introduced into the cells by EP}

As suggested in the literature, short HV pulses alone are mostly not suitable for GET to skin due to short electrophoretic distance. Moreover, HV pulses primarily transfect the cells in the superficial mouse skin layers, whereas the longer, low voltage pulses ( $\mathrm{MV}$ in our case) promote transfection of deeper skin layers [3], including the skin muscles that are present in mouse skin. This is probably the reason why the difference in the expression levels between HV pulses and HV-MV or MV pulses was not as prominent on the first days after GET, but, it was less efficacious when measured 14 days after GET. In simulations, HV pulses proved to be efficient in combination with MV pulses (also in the literature named LV - low voltage pulses), which is in agreement with experimental observations. Moreover, our simulations support the presumable role of $\mathrm{HV}$ pulse as a permeabilizing pulse and MV pulse as electrophoretic pulse. Despite the shorter electrophoretic distance and smaller local conductive pathway sizes achieved by $4 \mathrm{MV}$ pulses, the $\mathrm{HV}-\mathrm{MV}$ protocol proved to be more efficient than MV protocol with twice as many MV pulses. This confirms the importance of increasing the volume of reversible EP. The difference in electroporated volume between MV and HV-MV protocols may be even larger taking into account the higher local conductive pathway density achieved by HV pulses, which was neglected in our simulations.

The differences regarding unipolar and bipolar pulses cannot be explained by our numerical model, since both parameters, EP and electrophoresis, depend only on the norm of the electric field. However, we can stipulate that the reason that a better transfection efficacy of bipolar pulses which was shown previously in vitro [29], was not achieved, as was also reported for in vivo experiments [30], may lie in different sizes of electroporated areas on each side of the cell. The side of the cell facing the anode is hyperpolarized, meaning it reaches the threshold transmembrane potential for EP before the other side of the cell, which is depolarized [58]. By increasing the electric field intensity, the threshold is also reached at the other side of the cell, but the area being electroporated is always smaller than the one on the hyperpolarized side [59], [60]. When using unipolar pulses, plasmid DNA encounters the depolarized side of the cell. The bipolar pulses, on the other hand, enable the contact with the larger electroporated area on the hyperpolarized side, therefore improving the transfection efficacy. We have to keep in mind, however, that changing the orientation of electric field can also have a negative impact on the transfection efficacy. The action of electrophoretic forces in the opposite direction can, namely, lead to partial removal of the DNA from the cell membrane. Due to this effect, unipolar pulses proved to be better choice than bipolar at delays shorter than $100 \mu$ s between subsequent pulses [11]. The lag between the electrophoretic MV pulse and the next HV pulse, which is close to $1 \mathrm{~s}$ in our experiments, is sufficient for formation of a stable plasmid-membrane complex, but still enables a partial loss of DNA-cell membrane interactions [11].

The low level of HSP induction after EP regardless of the pulse parameters used show that although the cells exposed to EP sense stress, it is at a very low level. Interestingly, although all of the tested pulse parameters induced similar level of HSP expression, there were significant differences in their transfection efficacy for plasmid DNA. Implying, that there is no connection between the induced stress levels and transfection efficacy.

\section{CONCLUSION}

The application of electric pulses, commonly used for GET to skin, results in the low level of HSP induction. This indicates that surviving cells experience low level of thermal and EP induced stress. According to the model, both types of stress (thermal and EP induced) contribute to HSP induction, since thermal stress alone is not sufficient to explain the measurements. Namely, the volume of cells experiencing thermal stress largely overlaps with the volume of irreversible 
EP, which prevents HSP expression. In contrast to similar levels of HSP expression, induced by all tested electric pulse protocols, significant differences were observed in transfection efficiencies. As expected, the combination of $\mathrm{HV}$ and MV pulses achieved higher levels of expression compared to MV and $\mathrm{HV}$ electric pulse alone. However, deeper understanding of the processes involved in EP mediated gene delivery is required to further improve the efficacy of GET.

\section{ACKNOWLEDGMENT}

This work was supported by grants of the InterRegion Aquitaine-Midi-Pyrénées Project $\left(\mathrm{N}^{\circ} 12050112\right)$, by grants of the Region Midi-Pyrénées $\left(\mathrm{N}^{\circ} 11052700\right.$ and $\left.\mathrm{N}^{\circ} 13050740\right)$ and by the Slovenian Research Agency (Research programme P20249 and funding to TF). Research was conducted within the scope of the Electroporation in Biology and Medicine European Associated Laboratory (LEA EBAM) and resulted from the networking efforts of the COST Action TD1104 (http://www.electroporation.net). We thank the Toulouse Réseau Imagerie and Anexplo core IPBS facilities (Genotoul, Toulouse, France).

\section{REFERENCES}

[1] S. H. T. Jorritsma et al., "Delivery methods to increase cellular uptake and immunogenicity of DNA vaccines," Vaccine, vol. 34, no. 46, pp. 5488-5494, Nov. 2016.

[2] S. Pierini et al., "Trial watch: DNA-based vaccines for oncological indications," Oncoimmunology, vol. 6, no. 12, p. e1398878, Dec. 2017.

[3] S. Kos et al., "Electrotransfer parameters as a tool for controlled and targeted gene expression in skin.," Mol. Ther. Nucleic Acids, vol. 5, no. 8, p. e356, Aug. 2016.

[4] J.-M. Escoffre et al., "Gene electrotransfer: from biophysical mechanisms to in vivo applications," Biophys. Rev., vol. 1, no. 4, pp. 177-184, Dec. 2009.

[5] Gothelf and J. Gehl, "Gene electrotransfer to skin; review of existing literature and clinical perspectives.," Curr. Gene Ther., vol. 10, no. 4, pp. 287-99, Aug. 2010.

[6] L. C. Heller and R. Heller, "In Vivo Electroporation for Gene Therapy," Hum. Gene Ther., vol. 17, no. 9, pp. 890-897, Sep. 2006.

[7] R. Heller et al., "Electrically Mediated Delivery of Plasmid DNA to the Skin, Using a Multielectrode Array," Hum. Gene Ther., vol. 21, no. 3, pp. 357-362, Mar. 2010.

[8] N. Pavselj and V. Préat, "DNA electrotransfer into the skin using a combination of one high- and one low-voltage pulse," J. Control. Release, vol. 106, no. 3, pp. 407-415, Sep. 2005.

[9] C. L. Trimble et al., "Safety, efficacy, and immunogenicity of VGX-3100, a therapeutic synthetic DNA vaccine targeting human papillomavirus 16 and 18 E6 and E7 proteins for cervical intraepithelial neoplasia 2/3: a randomised, double-blind, placebo-controlled phase $2 \mathrm{~b}$ trial.," Lancet (London, England), vol. 386, no. 10008, pp. 2078-2088, Nov. 2015

[10] C. Faurie et al., "Cell and Animal Imaging of Electrically Mediated Gene Transfer," DNA Cell Biol., vol. 22, no. 12, pp. 777-783, Dec. 2003.

[11] C. Faurie et al., "Electro-mediated gene transfer and expression are controlled by the life-time of DNA/membrane complex formation," $J$. Gene Med., vol. 12, no. 1, pp. 117-125, Jan. 2010.

[12] M. Golzio et al., "Direct visualization at the single-cell level of electrically mediated gene delivery," Proc. Natl. Acad. Sci., vol. 99, no. 3, pp. 1292-1297, Feb. 2002

[13] A. Paganin-Gioanni et al., "Direct visualization at the single-cell level of siRNA electrotransfer into cancer cells.," Proc. Natl. Acad. Sci. U. S. A., vol. 108, no. 26, pp. 10443-7, Jun. 2011.

[14] C. Rosazza et al., "Endocytosis and Endosomal Trafficking of DNA After Gene Electrotransfer In Vitro.," Mol. Ther. Nucleic Acids, vol. 5, no. 2, p. e286, Feb. 2016

[15] G. Tevz et al., "Gene Electrotransfer into Murine Skeletal Muscle: A Systematic Analysis of Parameters for Long-term Gene Expression," Technol. Cancer Res. Treat., vol. 7, no. 2, pp. 91-101, Apr. 2008.
[16] F. André et al., "Efficiency of high-and low-voltage pulse combinations for gene electrotransfer in muscle, liver, tumor, and skin." Hum Gene Ther, vol. 19, no. 11, pp. 1261-71, 2008.

[17] K. Znidar et al., "Cytosolic DNA Sensor Upregulation Accompanies DNA Electrotransfer in B16.F10 Melanoma Cells," Mol. Ther. - Nucleic Acids, vol. 5, no. 6, p. e322, Jun. 2016.

[18] R. Voellmy, "Transduction of the stress signal and mechanisms of transcriptional regulation of heat shock/stress protein gene expression in higher eukaryotes.," Crit. Rev. Eukaryot. Gene Expr., vol. 4, no. 4, pp. 357-401, 1994.

[19] V. Mlakar et al., "Electric pulses used in electrochemotherapy and electrogene therapy do not significantly change the expression profile of genes involved in the development of cancer in malignant melanoma cells.," BMC Cancer, vol. 9, p. 299, 2009.

[20] V. Todorovic et al., "Metastatic potential of melanoma cells is not affected by electrochemotherapy," Melanoma Res., vol. 21, no. 3, pp. 196-205, Jun. 2011.

[21] X. de la Rosa et al., "In vivo imaging of induction of heat-shock protein70 gene expression with fluorescence reflectance imaging and intravital confocal microscopy following brain ischaemia in reporter mice," Eur. J. Nucl. Med. Mol. Imaging, vol. 40, no. 3, pp. 426-438, Feb. 2013.

[22] P.-Y. Fortin et al., "Dual-reporter in vivo imaging of transient and inducible heat-shock promoter activation," Biomed. Opt. Express, vol. 5, no. 2, p. 457, Feb. 2014.

[23] J. T. Beckham et al., "Assessment of Cellular Response to Thermal Laser Injury Through Bioluminescence Imaging of Heat Shock Protein 70," Photochem. Photobiol., vol. 79, no. 1, pp. 76-85, Jan. 2004.

[24] R. Deckers et al., "Arrhenius analysis of the relationship between hyperthermia and Hsp70 promoter activation: a comparison between ex vivo and in vivo data.," Int. J. Hyperthermia, vol. 28, no. 5, pp. 441-50, Jan. 2012.

[25] G. Bertino et al., "European Research on Electrochemotherapy in Head and Neck Cancer (EURECA) project: Results of the treatment of skin cancer," Eur. J. Cancer, vol. 63, pp. 41-52, Aug. 2016.

[26] M. Cemazar et al., "Control by pulse parameters of DNA electrotransfer into solid tumors in mice," Gene Ther., vol. 16, no. 5, pp. 635-644, May 2009.

[27] S. Pedron-Mazoyer et al. "New anti angiogenesis developments through electro-immunization: Optimization by in vivo optical imaging of intradermal electrogenetransfer," Biochim. Biophys. Acta - Gen. Subj., vol. 1770, no. 1, pp. 137-142, Jan. 2007.

[28] S. Mazères et al., "Non invasive contact electrodes for in vivo localized cutaneous electropulsation and associated drug and nucleic acid delivery," J. Control. Release, vol. 134, no. 2, pp. 125-131, Mar. 2009.

[29] J. Orio, M. Coustets et al., "Electric Field Orientation for Gene Delivery Using High-Voltage and Low-Voltage Pulses," J. Membr. Biol., vol. 245, no. 10, pp. 661-666, Oct. 2012

[30] V. Todorovic et al., "Changing electrode orientation, but not pulse polarity, increases the efficacy of gene electrotransfer to tumors in vivo," Bioelectrochemistry, vol. 100, pp. 119-127, Dec. 2014.

[31] J. Schindelin et al., "Fiji: an open-source platform for biological-image analysis," Nat. Methods, vol. 9, no. 7, pp. 676-682, Jul. 2012.

[32] C. P. Sabino et al., "The optical properties of mouse skin in the visible and near infrared spectral regions," J. Photochem. Photobiol. B Biol., vol. 160, pp. 72-78, Jul. 2016.

[33] N. Pavselj et al., "A Numerical Model of Skin Electropermeabilization Based on In Vivo Experiments," Ann. Biomed. Eng., vol. 35, no. 12, pp. 2138-2144, Nov. 2007.

[34] U. F. Pliquett et al., "Imaging of fluorescent molecule and small ion transport through human stratum corneum during high voltage pulsing: localized transport regions are involved.," Biophys. Chem., vol. 58, no. 12, pp. 185-204, Jan. 1996.

[35] N. Pavselj and D. Miklavcic, "Resistive heating and electropermeabilization of skin tissue during in vivo electroporation: A coupled nonlinear finite element model," Int. J. Heat Mass Transf., vol. 54, no. 11-12, pp. 2294-2302, May 2011.

[36] S. Becker et al., "Transdermal transport pathway creation: Electroporation pulse order," Math. Biosci., vol. 257, pp. 60-68, Nov. 2014.

[37] A. Ivorra et al., "Use of conductive gels for electric field homogenization increases the antitumor efficacy of electroporation therapies.," Phys. Med. Biol., vol. 53, no. 22, pp. 6605-18, Nov. 2008.

[38] D. E. Chafai et al., "Assessment of the electrochemical effects of pulsed electric fields in a biological cell suspension," Bioelectrochemistry, vol. 106, pp. 249-257, 2015. 
[39] A. Silve et al., "Impact of external medium conductivity on cell membrane electropermeabilization by microsecond and nanosecond electric pulses," Sci. Rep., vol. 6, no. 1, p. 19957, Apr. 2016.

[40] G. Saulis et al., "Theoretical Analysis and Experimental Determination of the Relationships Between the Parameters of the Electric Field Pulse Required to Electroporate the Cells," IEEE Trans. Plasma Sci., vol. 41, no. 10, pp. 2913-2919, Oct. 2013.

[41] G. Pucihar et al., "Equivalent Pulse Parameters for Electroporation," IEEE Trans. Biomed. Eng., vol. 58, no. 11, pp. 3279-3288, Nov. 2011.

[42] F. C. Henriques, "Studies of thermal injury; the predictability and the significance of thermally induced rate processes leading to irreversible epidermal injury.," Arch. Pathol., vol. 43, no. 5, pp. 489-502, May 1947.

[43] A. M. Stoll and L. C. Greene, "Relationship between pain and tissue damage due to thermal radiation.," J. Appl. Physiol., vol. 14, no. 3, pp. 373-82, May 1959.

[44] M. N. Rylander et al., "Optimizing heat shock protein expression induced by prostate cancer laser therapy through predictive computational models," J. Biomed. Opt., vol. 11, no. 4, p. 041113, 2006.

[45] H. Zhao et al., "Emission spectra of bioluminescent reporters and interaction with mammalian tissue determine the sensitivity of detection in vivo," J. Biomed. Opt., vol. 10, no. 4, p. 041210, 2005.

[46] B. W. Rice et al., "In vivo imaging of light-emitting probes.," J. Biomed. Opt., vol. 6, no. 4, pp. 432-40, Oct. 2001.

[47] S. Haberl et al., "Effect of different parameters used for in vitro gene electrotransfer on gene expression efficiency, cell viability and visualization of plasmid DNA at the membrane level," J. Gene Med., vol. 15, no. 5, pp. 169-181, May 2013.

[48] M. Pavlin and M. Kandušer, "New insights into the mechanisms of gene electrotransfer--experimental and theoretical analysis.,"Sci. Rep., vol. 5, p. 9132, Mar. 2015.

[49] L. Lambricht et al., "Clinical potential of electroporation for gene therapy and DNA vaccine delivery," Expert Opin. Drug Deliv., vol. 13, no. 2, pp. 295-310, 2016.

[50] M. Kranjc et al., "Predicting irreversible electroporation-induced tissue damage by means of magnetic resonance electrical impedance tomography," Sci. Rep., vol. 7, no. 1, p. 10323, Dec. 2017.

[51] W. Hundt et al., "In Vitro Effect of Focused Ultrasound or Thermal Stress on HSP70 Expression and Cell Viability in Three Tumor Cell Lines," Acad. Radiol., vol. 14, no. 7, pp. 859-870, 2007.

[52] C. E. O'Connell-Rodwell et al., "In vivo analysis of heat-shock-protein70 induction following pulsed laser irradiation in a transgenic reporter mouse," J. Biomed. Opt., vol. 13, no. 3, p. 030501, 2008.

[53] G. J. Wilmink et al., "In-vivo optical imaging of hsp70 expression to assess collateral tissue damage associated with infrared laser ablation of skin," J. Biomed. Opt., vol. 13, no. 5, p. 054066, 2008.

[54] M. A. Mackanos and C. H. Contag, "Pulse duration determines levels of Hsp70 induction in tissues following laser irradiation.," J. Biomed. Opt., vol. 16, no. 7, p. 078002, Jul. 2011.

[55] R. C. G. Martin et al., "Irreversible Electroporation Therapy in the Management of Locally Advanced Pancreatic Adenocarcinoma," J. Am. Coll. Surg., vol. 215, no. 3, pp. 361-369, Sep. 2012.

[56] B. Markelc et al., "In vivo molecular imaging and histological analysis of changes induced by electric pulses used for plasmid DNA electrotransfer to the skin: a study in a dorsal window chamber in mice.," J. Membr. Biol., vol. 245, no. 9, pp. 545-54, Sep. 2012.

[57] G. Sersa et al., "Vascular disrupting action of electroporation and electrochemotherapy with bleomycin in murine sarcoma.," $\mathrm{Br}$. J. Cancer, vol. 98 , no. 2, pp. 388-98, Jan. 2008.

[58] T. Kotnik et al., "Cell membrane electropermeabilization by symmetrical bipolar rectangular pulses. Part I. Increased efficiency of permeabilization.," Bioelectrochemistry, vol. 54, no. 1, pp. 83-90, Aug. 2001.

[59] K. Schwister and B. Deuticke, "Formation and properties of aqueous leaks induced in human erythrocytes by electrical breakdown.," Biochim. Biophys. Acta, vol. 816, no. 2, pp. 332-48, Jun. 1985.

[60] C. Rosazza et al., "Gene Electrotransfer: A Mechanistic Perspective.," Curr. Gene Ther., vol. 16, no. 2, pp. 98-129, 2016. 